\title{
Characteristics Associated with the Postprandial Hypotensive Response in Falling Older Adults
}

\author{
Kenneth M. Madden, ${ }^{1,2}$ Boris Feldman, ${ }^{1}$ and Graydon S. Meneilly'
}

\begin{abstract}
RÉSUMÉ
Il a été démontré que l'intensité de la réponse hypotensive postprandiale (RHP) peut constituer un facteur de risque pour les chutes, les fractures et le décès. Bien que ce risque ait été bien établi, les cliniques de chutes font rarement des analyses liées aux repas, en raison de contraintes logistiques. Afin de mieux cibler les patients à risque de RHP parmi les personnes âgées affectées par des chutes, cette étude a examiné les caractéristiques individuelles associées à des RHP plus intenses. Cinquante-deux patients (âge moyen : 77,8 \pm 0,9 ans, 29 femmes, 23 hommes) référés par des cliniques de prévention des chutes ont été recrutés pour un repas-test de 90 minutes. Les variables significatives ont ensuite été insérées dans un modèle linéaire multivarié incluant l'âge, le sexe, la présence de diabète, la présence d'hypertension, la pression systolique de base (PSB) et la chute de la PSB orthostatique. Bien que de plus amples recherches soient nécessaires, notre étude suggère que les hommes, les patients présentant une tension artérielle élevée et ceux avec une chute orthostatique pourraient être plus à risque de réponses hémodynamiques postprandiales plus intenses.
\end{abstract}

\begin{abstract}
The magnitude of the postprandial hypotensive (PPH) response has been shown to be an independent risk factor for falls, fractures, and death. Despite this well-established risk, meal tests are rarely done in the falls clinic setting because of logistical issues. In order to better target potential PPH patients among older falling adults, this study examines which subject characteristics are associated with larger PPH responses. A total of 52 falls clinic patients (mean age $77.8 \pm 0.9$ years, 29 women, 23 men) were recruited for a 90 minute meal test. Significant variables were then entered into a stepwise multivariate linear model containing age, sex, presence of diabetes, presence of hypertension, baseline systolic blood pressure (SBP), and the orthostatic drop in SBP. Although further work is required, our study suggests that men, patients with higher blood pressure, and patients with an orthostatic drop might be more likely to have higher postprandial hemodynamic responses.
\end{abstract}

1 Gerontology and Diabetes Research Laboratory, Division of Geriatric Medicine, Department of Medicine, University of British Columbia, Vancouver, British Columbia.

2 Centre for Hip Health and Mobility, University of British Columbia, Vancouver, British Columbia.

* This work was supported by the Allan M. McGavin Foundation and the Heart and Stroke Foundation of Canada.

Manuscript received: / manuscrit reçu : 13/07/18

Manuscript accepted: / manuscrit accepté : 10/11/18

Mots-clés : vieillissement, hypotension postprandiale, chutes, syncope

Keywords: aging, postprandial hypotension, falls, syncope

La correspondance et les demandes de tirés-à-part doivent être adressées à : / Correspondence and requests for offprints should be sent to:

Kenneth M. Madden, M.D.

Department of Geriatric Medicine

Room 7185-Gordon and Leslie Diamond Health Care Centre

2775 Laurel St.

Vancouver, BC

Canada, V5Z 1M9

(kmmadden@mail.ubc.ca)

Canadian Journal on Aging / La Revue canadienne du vieillissement 38 (4) : 434-440 (2019)

Copyright (C) Canadian Association on Gerontology 2019. This is an Open Access article, distributed under the terms of the

Creative Commons Attribution licence (http://creativecommons.org/licenses/by/4.0/), which permits unrestricted re-use,

distribution, and reproduction in any medium, provided the original work is properly cited. 


\section{Background}

A decrease in blood pressure after eating, a condition referred to as postprandial hypotension (PPH) is associated with an increased risk for falls, fractures (Aronow \& Ahn, 1997), and increased mortality (Aronow \& Ahn, 1997). PPH-related falls in older adults also result in dangerous and expensive outcomes such as hip fractures, institutionalization, and increased rates of hospitalization (Do, Chang, Kuran, \& Thompson, 2015). The often vague symptomatology associated with this condition (Kohara et al., 1999) unfortunately makes PPH a diagnosis that is frequently overlooked, although some studies have suggested that it accounts for approximately 15 per cent of all fainting-related falls in older adults (Jansen \& Lipsitz, 1995).

The only definitive method to screen for $\mathrm{PPH}$ is with a meal test (Trahair, Horowitz, \& Jones, 2014), a process that is both logistically difficult and time consuming. The large number of older adults who are currently injured by falls (Davis, Robertson, Comans, \& Scuffham, 2011), and the ongoing demographic shift that is increasing the prevalence of falls (Chand \& Tung, 2015) makes the strategy of screening all falls clinic patients not logistically practical. A better understanding of which patient characteristics are associated with higher $\mathrm{PPH}$ responses would help falls clinics better target patients for meal testing. Previous investigations have shown an association among PPH and increasing age and hypertension (Zou et al., 2015), but this work was done on healthy, highly screened, non-falling volunteers. From a clinical perspective, $\mathrm{PPH}$ has also been anecdotally linked with several modifiable risk factors in older adults, such as polypharmacy, anti-hypertensive drugs, autonomic dysfunction, dehydration, and aortic stenosis (Jansen, 2005). The current study attempts, using meal tests in a falls clinic population, to see which subject characteristics are most associated with an increased $\mathrm{PPH}$ response.

\section{Materials and Methods}

\section{Subjects}

All subjects were recruited sequentially from January 2014 to July 2018 and had to be over 65 years of age. All subjects were referred to the Division of Geriatric Medicine falls clinic at Vancouver General Hospital. None of the subjects had a swallowing or oral issue preventing the ability to complete a meal test. All subjects gave written consent and received approval by the Human Subjects Committee of the University of British Columbia.

\section{Meal Tests}

Meal Testing

Each meal test lasted 90 minutes and all subjects were examined in the fasted state; all sessions took place between 0700 and 1200 to avoid bias caused by circadian rhythms. Each subject rested in the supine position for 30 minutes prior to the start of data collection in order to reach steady state. Subjects were told to refrain from consuming alcohol or caffeine and also to refrain from vigorous exercise for the 24 hours prior to each session. Anti-hypertensive medications were not administered the morning of the meal test. All tests occurred in a room that was quiet and held at a constant temperature $\left(25^{\circ} \pm 1^{\circ} \mathrm{C}\right)$. The standardized meal consisted of a 1,050 kJ standardized meal substitute (containing $38 \mathrm{~g}$ carbohydrates, $7.8 \mathrm{~g}$ fat, $9.4 \mathrm{~g}$ protein, and $3.4 \mathrm{~g}$ fibre) and was presented at a standardized temperature (refrigerated, $3.0 \pm 0.5^{\circ} \mathrm{C}$ ).

\section{Data Collection and Processing}

With each subject resting comfortably in the seated position, continuous beat-to-beat measures of blood pressure were collected at baseline and for a total of 90 minutes after standardized meal ingestion. All blood pressure signals were sampled at 1,000 Hz (Powerlab, AD Instruments) and digitized for later analysis.

Blood pressure was monitored with a Finometer (Finapres Medical Systems BV, The Netherlands). Through a finger cuff, the Finometer uses infrared plethysmography to measure beat-to-beat blood pressure non-invasively. The infrared plethysmography technique has been well established as a non-invasive measure of beat-to-beat blood pressure (Imholz, Wieling, van Montfrans, \& Wesseling, 1998) and has been validated against intra-arterial blood pressure monitoring in older adult subjects (Rongen et al., 1995). The Finometer also performs an additional return-to-flow calibration, as well as level correction and waveform filtering, allowing an accurate reconstruction of brachial artery pressures from infrared plethysmography data (Bos, van Goudoever, van Montfrans, van den Meiracker, \& Wesseling, 1996; Guelen et al., 2003). Beat-to-beat measures of systolic (SBP), mean (MBP), and diastolic (DBP) blood pressure were obtained using commercial software (Beatscope, Finapres Medical Systems BV, The Netherlands). Blood pressure measures were averaged for each 5 minute data window during the meal test.

The presence of a PPH event was defined as a decrease in SBP of $20 \mathrm{~mm} \mathrm{Hg}$ during one of the data windows within 90 minutes of ingesting the standardized meal (Jansen \& Hoefnagels, 1990). The number of "PPH events" $\left(\mathrm{PPH}_{\text {num }}\right)$ was defined as the number of times 
during a meal test that a subject met PPH criteria. The maximum SBP decrease $\left(\mathrm{PPH}_{\max }\right)$ was calculated for each 5 minute data window and averaged. The data were all analyzed post-collection in a blinded fashion, and each segment of blood pressure data was manually examined to exclude artifacts. Immediately on arriving at the laboratory, subjects had their blood pressure measured (Welch Allyn, ABPM 7100) for orthostatic changes three times, and the results were averaged. Blood pressure was measured in the supine position and after 3 minutes standing upright (Ziegler et al., 1992).

\section{Statistical Methods}

Our two response variables were $\mathrm{PPH}_{\text {max }}$ and $\mathrm{PPH}_{\text {num }}$. Our predictor variables were age, sex, body mass index (BMI), the presence of diabetes, the presence of hypertension, baseline SBP, and orthostatic drop in SBP. Scatter plots were visually inspected for outlier data and density plots were examined to identify skewing of the data. Any predictors that demonstrated skewing were logarithmically transformed (base 10) prior to both the univariate and multivariate analyses. After our initial model, model simplification was accomplished through a tiered approach using a stepwise method. Each successive regression model was generated by removing the least significant predictor with a $p$ value of $>.10$. After each predictor was removed, Akaike's information criterion (AIC) was calculated until the smallest AIC was obtained (Crawley, 2011). Tolerance values and variance inflation factors were examined for multicollinearity, to ensure that the assumptions of the multivariate regression were met. Plots of residuals and a QQ plot were examined in our final minimum effective model. The $\mathrm{R}$ core software package version 3.4.2 was used for statistical analysis with a significance level of $p<.05$ (R Core Team, 2017). All data analysis was done in a blinded fashion and the format mean \pm standard error was used to express results.

\section{Results}

\section{Subject Characteristics}

Of the first 98 subjects approached, 52 agreed to participate in the study ( 29 women and 23 men). There were no withdrawals from the study. Mean age was $77.9 \pm$ 0.9 years with an age range of $67-92$ years. Twenty-five were diagnosed with diabetes, 33 had a diagnosis of hypertension, 3 had aortic stenosis, 4 had a diagnosis of systolic heart failure, and the mean BMI was $29.8 \pm$ 1.1. None of the subjects had Parkinson's disease or autonomic neuropathy. Subjects' baseline blood pressure prior to the administration of the standardized meal was $145 \pm 3 / 75 \pm 1 \mathrm{~mm} \mathrm{Hg}$, with a mean blood pressure of $98 \pm 1 \mathrm{~mm} \mathrm{Hg}$. The mean orthostatic decrease in SBP was $4 \pm 3$. Thirty-one subjects met the criteria for polypharmacy, if one defined polypharmacy as the use of five or more medications (Gnjidic et al., 2012).

\section{Meal Test Results}

The mean maximum decrease in SBP observed in each 5 minute data window was $12 \pm 5 \mathrm{~mm} \mathrm{Hg}$. The mean postprandial response to the meal test was an average increase in SBP by $1 \pm 3 \mathrm{~mm} \mathrm{Hg}$. There was an average of $4 \pm 1$ observed $\mathrm{PPH}$ events during the 90 minute meal test.

\section{Postprandial Response and Subject Characteristics (Univariate Analysis, Table 1)}

No skewing was detected on inspection of the predictor variable density plots and no transformation was required prior to the analysis. In our initial univariate analysis, the magnitude of the orthostatic drop showed a significant correlation with both $\mathrm{PPH}_{\max }$ and $\mathrm{PPH}_{\text {num }}$ while preprandial SBP showed a significant correlation with $\mathrm{PPH}_{\max }$ (see Table 1).

\section{Maximal Postprandial SBP Response and Subject} Characteristics (Multivariate Analysis, Table 2)

Similar to what was described previously, our predictor variables initially explained 52 per cent of the variance in $\mathrm{PPH}_{\max }(\mathrm{PPH}$, Max, Model 1, Table 2). The highest variance inflation factor (VIF) for Model 1 was 1.67 (the presence of hypertension), indicating no multicollinearity issues. Our minimal effective model (Table 2) demonstrated a positive association with male sex. The maximal decrease in SBP showed a linear association with the magnitude of the orthostatic drop and an inverse association with the baseline pre-meal test BP. In fact, an orthostatic decrease of $10 \mathrm{~mm} \mathrm{Hg}$ was associated with a $5 \mathrm{~mm} \mathrm{Hg}$ increase in the magnitude of the postprandial decrease in SBP (Figure 1).

\section{Number of PPH Events and Subject Characteristics (Multivariate Analysis, Table 2)}

Fifty-two per cent of the variance in the number of $\mathrm{PPH}$ events observed was explained by our initial model containing age, baseline SBP, orthostatic drop in SBP, sex, the presence of diabetes, and the presence of hypertension $\left(\mathrm{PPH}_{\text {num, }}\right.$ Model 1, Table 2). The highest VIF was 1.69 (the presence of hypertension), indicating a lack of multicollinearity issues. Our minimal effective model contained BMI, the presence of hypertension, and orthostatic drop; a higher BMI, the presence of hypertension, and a higher orthostatic drop were all positively associated with a larger number of $\mathrm{PPH}$ events during the meal test. 
Table 1: Univariate regression analysis $(n=52)$

\begin{tabular}{llcc}
\hline Response Variable & Predictors & $\boldsymbol{R}(\mathbf{C l}$ 95\%) & $\boldsymbol{p}$ Value \\
\hline $\mathrm{PPH}_{\max }$ & Age & $.102(-.178-.368)$ & .474 \\
& BMI & $.032(-.295-.353)$ & .849 \\
& Baseline SBP & $-.524(-.290-.698)$ & $<.001^{*}$ \\
& Orthostatic drop & $.458(.206-.658)$ & $<.001^{*}$ \\
$\mathrm{PPH}_{\text {num }}$ & Age & $.072(-.205-.338)$ & .614 \\
& BMI & $.134(-.199-.439)$ & .429 \\
& Baseline SBP & $-.148(-.130-.404)$ & .296 \\
& Orthostatic drop & $.491(.249-.675)$ & $<.001^{*}$ \\
\hline
\end{tabular}

Note. $\mathrm{PPH}=$ postprandial hypotension; $\mathrm{PPH}_{\max }=$ average maximal change in blood pressure; $\mathrm{PPH}_{\text {num }}=$ number of $\mathrm{PPH}$ events observed; $\mathrm{BMI}=$ body mass index; $\mathrm{SBP}=$ systolic blood pressure; $R=$ Pearson Correlation Coefficient; $\mathrm{Cl}=$ confidence interval, ${ }^{*} p<.05$.

\section{Discussion}

Principal Findings

Larger postprandial responses $\left(\mathrm{PPH}_{\max }\right)$ were associated with being of the male biological sex and having a larger orthostatic drop. There was more postprandial hemodynamic instability (higher number of $\mathrm{PPH}$ events) in subjects with higher BMIs, and in subjects with hypertension and with a higher orthostatic drop.

\section{Previous Work}

Despite the fact that $\mathrm{PPH}$ has a high prevalence (Yu, Song, \& Kim, 2002) and associated morbidity (Aronow \& Ahn, 1997), the risk factors and overall epidemiology of this condition remains "undefined" (O'Mara \& Lyons, 2002). Previous work has attempted to determine risk factors in inpatient populations (Puisieux et al., 2000), healthy community volunteers (Yu et al., 2002; Zou et al., 2015), and older adults in residential care (Aronow \& Ahn, 1997; Jansen, KellyGagnon, \& Lipsitz, 1996; Le Couteur, Fisher, Davis, \&
McLean, 2003). To our knowledge, despite the high clinical relevance, no previous work has examined a falls clinic population for characteristics associated with a higher PPH response (the focus of the current study).

Preprandial Blood Pressure and the Postprandial Response Our study demonstrated that a lower preprandial SBP was associated with higher maximal decreases in postprandial SBP. This result is congruent with previous work in community dwelling volunteers (Yu et al., 2002) and inpatients (Puisieux et al., 2000) showing that lower preprandial SBPs are associated with a larger PPH response, providing a likely explanation for the association between PPH and BP lowering medications observed in long-term care patients (Aronow \& Ahn, 1997).

\section{Risk Factors for Autonomic Dysfunction and the Postprandial Response}

$\mathrm{PPH}$ has shown a strong association with autonomic dysfunction (Kooner et al., 1989), and is a welldocumented etiology for PPH in both autonomic neuropathy (Sasaki, Kitaoka, \& Ohsawa, 1992) and spinal cord injuries (Catz, Mendelson, \& Solzi, 1992). Chronic hypertension is a well-documented cause of autonomic dysfunction (Fagard, Pardaens, \& Staessen, 2001), and past studies of older community-dwelling adults have shown an association between having a diagnosis of hypertension and a larger PPH response (Zou et al., 2015), similar to the results of the current study. Obesity has a well-documented association with autonomic dysfunction (Rossi et al., 1989) and increased BP variability (Piccirillo et al., 1998). Our study is congruent with these results, demonstrating a strong association between a higher BMI and more observed PPH events. Previous work has suggested that the various neuroautonomic etiologies for syncope (such

Table 2: Stepwise multivariate regression analysis $(n=52)$

\begin{tabular}{|c|c|c|c|c|}
\hline & $R^{2}$ & Unstandardized $\beta$ (SE) & Standardized $\beta$ & $p$ Value \\
\hline $\mathrm{PPH}_{\max ,}$ MEM F(4,47) $=11.520$ & 0.506 & & & $<.001$ \\
\hline Sex & & $-18.826(7.771)$ & $-.535(.222)$ & $.020^{*}$ \\
\hline Orthostatic drop & & $.515(.216)$ & $-.269(.114)$ & $.021^{*}$ \\
\hline Baseline SBP & & $-.581(.206)$ & $.281(.127)$ & $.007^{*}$ \\
\hline $\mathrm{PPH}_{\text {num }}, \mathrm{MEM} F(5,46)=6.073$ & 0.403 & & & $<.001$ \\
\hline Hypertension & & $3.773(1.514)$ & $.691(.277)$ & $.017^{*}$ \\
\hline Orthostatic drop & & $.194(.039)$ & $-.643(.130)$ & $<.001$ \\
\hline Baseline SBP & & $-.069(.040)$ & $-.246(.141)$ & .089 \\
\hline
\end{tabular}

Note. $M E M=$ minimal effective model; $\mathrm{PPH}=$ postprandial hypotension; $\mathrm{PPH}_{\max }=$ average maximal change in blood pressure; $\mathrm{PPH}_{\text {num }}=$ number of PPH events observed; $\mathrm{BMI}=$ body mass index; SBP $=$ systolic blood pressure; $R^{2}=$ coefficient of determination; SE - standard error; $\beta=$ beta coefficient, ${ }^{*} p<.05$ 


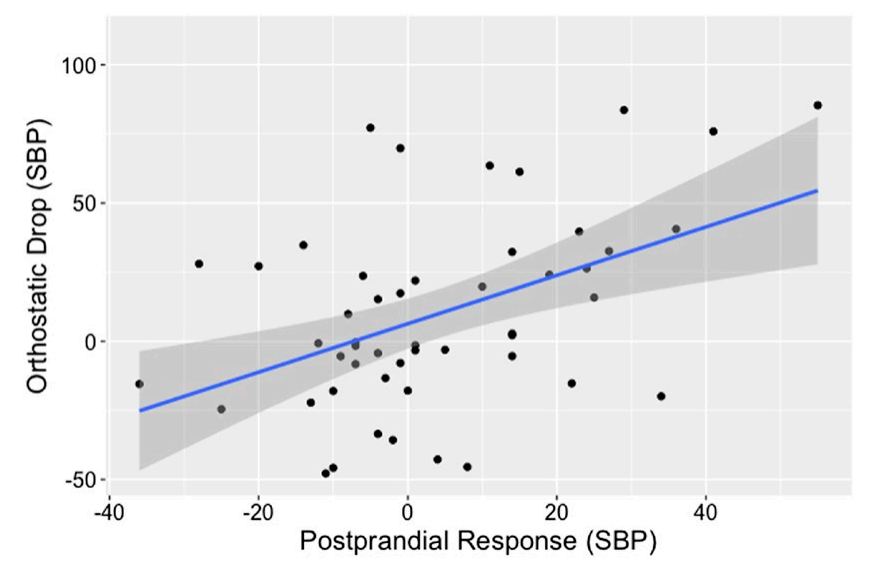

Figure 1: Orthostatic drop versus maximal postprandial hypotensive response (systolic blood pressure [SBP]). As shown by a plot of the maximal postprandial response versus orthostatic drop for each subject (black dots), an increase in orthostatic intolerance (SBP) is positively associated with a higher maximal postprandial decrease in SBP. The plotted linear regression (blue line) demonstrates that an orthostatic decrease of $10 \mathrm{~mm} \mathrm{Hg}$ was associated with a $5 \mathrm{~mm} \mathrm{Hg}$ increase in the magnitude of the postprandial decrease in SBP.

as orthostatic hypotension and $\mathrm{PPH}$ ) have a tendency to cluster in the same patients (De Ruiter, Wold, Germans, Ruiter, \& Jansen, 2018). Our results support this, as we were able to demonstrate an association between a higher orthostatic drop and both larger observed maximal PPH responses and a larger number of observed PPH events.

\section{Other Risk Factors}

To our knowledge, our study was the first to examine the relationship between biological sex and $\mathrm{PPH}$, showing that men have an increased average and maximal PPH response compared with women. Although previous work has shown that men have been shown to have more frequent episodes of syncope (Sun, Emond, \& Camargo, 2004) and worse outcomes from syncope (Costantino et al., 2008), these results apply to all etiologies of syncope and were not specific for $\mathrm{PPH}$. We were unable to demonstrate any association between increasing age and the PPH response, which is consistent with some previous studies of older adults (Yu et al., 2002) but not with other studies found in the literature (Zou et al., 2015). Zou et al. (2015) had a much larger proportion of oldest-old subjects in their subject pool; perhaps this wider variability in age allowed them to detect an association that was not seen in our sample.

\section{Clinical Implications}

Because of the vagueness of the presenting symptoms, $\mathrm{PPH}$ is a poorly recognized condition (Trahair et al., 2014) that has a profound impact on the lives of older adults through an increase in both mortality and morbidity (Aronow \& Ahn, 1997). Screening with a meal test is logistically impractical for all patients who present to a falls clinic. The associations noted in our study suggest that further screening of unexplained fallers with a meal test or continuous ambulatory BP monitoring should be strongly considered in men, hypertensive patients, obese patients, those patients with orthostatic intolerance, and those patients with low resting BP.

\section{Limitations and Future Research}

Because of the observational methods used in this study, we can only determine associations among the different potential risk factors and the size of the $\mathrm{PPH}$ response. We are unable to make any conclusions about mechanisms underlying the observed increased $\mathrm{PPH}$ response in males, hypertensive patients, obese patients, and in those patients with low resting or orthostatic intolerance. Our study also did not measure syncope rates, so it is difficult to determine at what level the PPH response has a clinical significance. Further studies are needed to determine if any of these risk factors can be modified to prevent falls in the complex older adult patient with PPH.

\section{Conclusions}

Our study demonstrated an association between being male, having hypertension, higher BMIs, low resting $\mathrm{BP}$, and higher orthostatic drops and a larger $\mathrm{PPH}$ response.

\section{References}

Aronow, W. S., \& Ahn, C. (1997). Association of postprandial hypotension with incidence of falls, syncope, coronary events, stroke, and total mortality at 29-month follow-up in 499 older nursing home residents. Journal of the American Geriatrics Society, 45(9), 1051-1053.

Bos, W. J., van Goudoever, J., van Montfrans, G. A., van den Meiracker, A. H., \& Wesseling, K. H. (1996). Reconstruction of brachial artery pressure from noninvasive finger pressure measurements. Circulation, 94(8), 1870-1875.

Catz, A., Mendelson, L., \& Solzi, P. (1992). Symptomatic postprandial hypotension in high paraplegia. Case report. Paraplegia, 30(8), 582-586.

Chand, M., \& Tung, R. L. (2014). The aging of the world's population and its effects on global business. Academy of Management Perspectives, 28(4), 409-429.

Costantino, G., Perego, F., Dipaola, F., Borella, M., Galli, A., Cantoni, G., et al (2008). Short- and long-term prognosis 
of syncope, risk factors, and role of hospital admission: Results from the STePS (Short-Term Prognosis of Syncope) study. Journal of the American College of Cardiology, 51(3), 276-283.

Crawley, M. J. (2011). Statistics: An introduction using R. West Sussex: Wiley.

Davis, J. C., Robertson, M. C., Comans, T., \& Scuffham, P. A. (2011). Guidelines for conducting and reporting economic evaluation of fall prevention strategies. Osteoporosis International, 22(9), 2449-2459.

De Ruiter, S. C., Wold, J. F. H., Germans, T., Ruiter, J. H., \& Jansen, R. W. M. M. (2018). Multiple causes of syncope in the elderly: Diagnostic outcomes of a Dutch multidisciplinary syncope pathway. Europace, 20(5), 867-872.

Do, M. T., Chang, V. C., Kuran, N., \& Thompson, W. (2015). Fall-related injuries among Canadian seniors, 2005-2013: An analysis of the Canadian Community Health Survey. Health Promotion and Chronic Disease Prevention in Canada: Research, Policy and Practice, 35(7), 99 .

Fagard, R. H., Pardaens, K., \& Staessen, J. A. (2001). Relationships of heart rate and heart rate variability with conventional and ambulatory blood pressure in the population. Journal of Hypertension, 19(3), 389-397.

Gnjidic, D., Hilmer, S. N., Blyth, F. M., Naganathan, V., Waite, L., Seibel, M. J., et al (2012). Polypharmacy cutoff and outcomes: Five or more medicines were used to identify community-dwelling older men at risk of different adverse outcomes. Journal of Clinical Epidemiology, 65(9), 989-995.

Guelen, I., Westerhof, B. E., Van Der Sar, G. L., Van Montfrans, G. A., Kiemeneij, F., Wesseling, K. H., et al (2003). Finometer, finger pressure measurements with the possibility to reconstruct brachial pressure. Blood Pressure Monitoring, $8(1), 27-30$.

Imholz, B. P., Wieling, W., van Montfrans, G. A., \& Wesseling, K. H. (1998). Fifteen years experience with finger arterial pressure monitoring: Assessment of the technology. Cardiovascular Research, 38(3), 605-616.

Jansen, R. W. (2005). Postprandial hypotension: Simple treatment but difficulties with the diagnosis. The Journals of Gerontology. Series A, Biological Sciences and Medical Sciences, 60(10), 1268-1270.

Jansen, R. W., \& Hoefnagels, W. H. (1990). Postprandial blood pressure reduction. The Netherlands Journal of Medicine, $37(1-2), 80-88$.

Jansen, R. W., Kelly-Gagnon, M. M., \& Lipsitz, L. A. (1996). Intraindividual reproducibility of postprandial and orthostatic blood pressure changes in older nursing-home patients: Relationship with chronic use of cardiovascular medications. Journal of the American Geriatrics Society, 44(4), 383-389.
Jansen, R. W., \& Lipsitz, L. A. (1995). Postprandial hypotension: Epidemiology, pathophysiology, and clinical management. Annals of Internal Medicine, 122(4), 286-295.

Kohara, K., Jiang, Y., Igase, M., Takata, Y., Fukuoka, T., Okura, T, et al (1999). Postprandial hypotension is associated with asymptomatic cerebrovascular damage in essential hypertensive patients. Hypertension, 33(1 Pt 2), 565-568.

Kooner, J. S., Raimbach, S., Watson, L., Bannister, R., Peart, S., \& Mathias, C. J. (1989). Relationship between splanchnic vasodilation and postprandial hypotension in patients with primary autonomic failure. Journal of Hypertension. Supplement, 7(6), S40-S41.

Le Couteur, D. G., Fisher, A. A., Davis, M. W., \& McLean, A. J. (2003). Postprandial systolic blood pressure responses of older people in residential care: Association with risk of falling. Gerontology, 49(4), 260-264.

O'Mara, G., \& Lyons, D. (2002). Postprandial hypotension. Clinics in Geriatric Medicine, 18(2), 307-321.

Piccirillo, G., Vetta, F., Viola, E., Santagada, E., Ronzoni, S., Cacciafesta, M., et al (1998). Heart rate and blood pressure variability in obese normotensive subjects. International Journal of Obesity and Related Metabolic Disorders, 22(8), 741-750.

Puisieux, F., Bulckaen, H., Fauchais, A. L., Drumez, S., Salomez-Granier, F., \& Dewailly, P. (2000). Ambulatory blood pressure monitoring and postprandial hypotension in elderly persons with falls or syncopes. The Journals of Gerontology. Series A, Biological Sciences and Medical Sciences, 55(9), M535-M540.

R Core Team. R: A language and environment for statistical computing. Vienna: R Foundation for Statistical Computing. Retrieved from 28 September 2017 from https:// www.R-project.org/

Rongen, G. A., Bos, W. J., Lenders, J. W., van Montfrans, G. A., van Lier, H. J., van Goudoever, J., et al (1995). Comparison of intrabrachial and finger blood pressure in healthy elderly volunteers. American Journal of Hypertension, 8(3), 237-248

Rossi, M., Marti, G., Ricordi, L., Fornasari, G., Finardi, G., Fratino, P., et al (1989). Cardiac autonomic dysfunction in obese subjects. Clinical Science, 76(6), 567-572.

Sasaki, E., Kitaoka, H., \& Ohsawa, N. (1992). Postprandial hypotension in patients with non-insulin-dependent diabetes mellitus. Diabetes Research and Clinical Practice, 18(2), 113-121.

Sun, B. C., Emond, J. A., \& Camargo, C. A. (2004). Characteristics and admission patterns of patients presenting with syncope to US emergency departments, 19922000. Academic Emergency Medicine, 11(10), 1029-1034.

Trahair, L. G., Horowitz, M., \& Jones, K. L. (2014). Postprandial hypotension: A systematic review. Journal of the American Medical Directors Association, 15(6), 394-409. 
Yu, S.-J., Song, M.-S., \& Kim, H.-S. (2002). A Study on the prevalence and risk factors of postprandial hypotension among the community-dwelling aged. Journal of Korean Academy of Fundamentals of Nursing, 9(3), 434-446.

Ziegler, D., Laux, G., Dannehl, K., Spuler, M., Muhlen, H., Mayer, P., et al (1992). Assessment of cardiovascular autonomic function: Age-related normal ranges and reproducibility of spectral analysis, vector analysis, and standard tests of heart rate variation and blood pressure responses. Diabetic Medicine, 9(2), 166-175.

Zou, X., Cao, J., Li, J.-H., Hu, Y.-X., Guo, Y.-S., Si, Q.-J., \& Fan, L. (2015). Prevalence of and risk factors for postprandial hypotension in older Chinese men. Journal of Geriatric Cardiology: JGC, 12(6), 600-604. 